\title{
ANÁLISE DA ESTRUTURA DO SUJEITO PSÍQUICO EM COMPARAÇÃO COM DOIS PERSONAGENS LITERÁRIOS
}

\author{
A nalysis of the psychic subject structure in comparison with two literary characters
}

\section{Marta Regina de Leão D'Agord ${ }^{a}$, Julianna Godinho Dale Coutinhob, Mayara Squeff Janovikc, Gisele Milman Cervo ${ }^{c}$}

\footnotetext{
a D outora em Psicologia, Professora do D epartamento de Psicanálise ePsicopatologia do Instituto dePsicologia(UFRG S), Porto Alegre, RS - Brasil, e-mail: mdagord@ terra.com.br

b Acadêmica de Psicologia (UFRG S), Bolsista BIC-UFRG S, Porto Alegre, RS - Brasil.

c Acadêmica de Psicologia (UFRG S), Bolsista Programa PET, Porto Alegre, RS - Brasil.
}

\section{Resumo}

Este artigo, cujo plano de fundo são os contos fantásticos, "O Homem da Areia" e "A história de um quebra-nozes" de E. T. A. Hoffmann (1766-1822), tem por objetivo realizar uma análise dos personagens à luz da teoria psicanalítica. Utiliza-se o método comparativo para a elaboração de um paralelo entre os processos psíquicos no campo da teoria psicanalítica e algumas das características dos personagens das narrativas literárias. O s personagens escolhidos para uma análise comparativa do processo de constituição do sujeito psíquico são Natanael, de "O Homem da Areia", e Maria, de "A história de um quebra-nozes". O conto "O Homem da Areia", enfoca o encontro de Natanael como uma figura misteriosa que toma a forma ora de Coppelius, o advogado e alquimista, ora de Coppola, o vendedor de lentes e barômetros. N esse encontro, o que Natanael vive é terrorífico, na medida em que, para ele, as palavras não têm eficácia simbólica. Assim, o que poderia ter sido fantasia, se torna alucinação. No conto "A história de um quebra-nozes", aquilo que, na história maravilhosa, não encontrou uma solução, é transposto para outro plano, o plano da narrativa presente. Essa transposição equivale ao jogo simbólico próprio do brincar. 0 estudo mostra que as histórias de Natanael e Maria configuram, respectivamente, a foraclusão e o recalque do significante do desejo originário, enquanto modos diferentes de estruturação do sujeito psíquico.

Palavras-chave: Psicanálise. Literatura. Sujeito psíquico. 


\begin{abstract}
This paper, whose background are the fantastic tales "The Sandman" and "The Story of a nutcracker" by E. T. A. Hoffmann (1766-1822), aims to analyse the characters in the perspective of psychoanalytic theory. The comparative method is adopted to establish a parallel between the analysis of mental processes in the field of psychoanalytic theory and in the descriptions of characters in literary narratives. Aspects of the character of "The Sandman", Natanael, and of the character of "The story of a nutcracker", Maria, are analyzed in comparison with the process of formation of psychic subject. The story "The Sandman" focuses on the meeting of Natanael with a mysterious figure, that for sometimes takes the form of Coppelius, the lawyer and alchemist, and another times, the form of Coppola, the seller of lenses and barometers. At this meeting, Natanael lives something dreadful due to the lack of symbolic effectiveness of the words. So, what could be fantasy becomes hallucination. In the tale "The story of a nutcracker" what is unable to find a solution in the marvelous world is transposed to another plan, the plan of present narrative. The symbolic role in this transposition is equivalent to the symbolic role in playing. The study shows that the stories of Natanael and Maria represent, respectively, the foreclosure and the repression of the originating desire's significant, as different ways of the psychic subject structuring.
\end{abstract}

Keywords: Psychoanalysis. Literature. Psychic subject.

\section{INTRODUÇÃO}

Este trabalho tem por objetivo elaborar um paralelo entre conceitos da teoria psicanalítica do psicopatológico e as vicissitudes dos personagens das narrativas literárias. 0 sofrimento de um personagem literário, narrado e elaborado por um escritor, é comparado a um caso clínico. Emprega-se o método comparativo, oriundo da Literatura Comparada (Carvalhal, 1994). Este método caracteriza-se pela elaboração de contrastes e analogiasentredois campos. Napesquisa comparativa realizada neste estudo, alguns traços dos personagens são analisados à luz dateoria psicanalítica. 0 destaque de traços dos personagens tem estreita afinidade com a pesquisa psicanalítica enquanto construção do caso. Essa forma de pesquisa entende que o caso é originário de um processo de atenção equiflutuante de um pesquisador, para quem um determinado detalhe de discurso chama a atenção pelas ressonâncias na sequência discursiva. Nesse sentido, a construção de um caso ocorre à medida da elaboração do próprio pesquisador.

Assim, se um caso não é um paciente, mas a elaboração do psicanalista a partir da escuta clínica, não poderíamos aplicar esse mesmo método ao estudo de personagens literários? É essa a matriz metodológica que sustenta este estudo: 0 método psicanalítico e o método comparativo. 0 processo seguinte é a delimitação de uma obra. 0 trabalho aqui apresentado consistiu na análise comparativa de dois contos do gênero fantástico.

\section{0 fantástico na literatura}

O fantástico é um gênero literário caracterizado pela presença de um fenômeno sobrenatural. Esse gênero interessa à psicopatologia na medida em que as aparições sobrenaturais podem ser relacionadas a vivências inconscientes. Calvino (2004, p. 9) compara o elemento sobrenatural, na narrativa fantástica, "à irrupção do inconsciente, do reprimido, do esquecido, do que se distanciou da nossa atenção racional."

O sobrenatural está presente, igualmente, nos contos de fadas, mas a expressão "era uma vez" o localiza em um tempo distante e fictício, sem relação com a realidade atual. No fantástico, como destaca Caillois (1997), as aparições sobrenaturais irrompem no mundo cotidiano dos seus personagens, de modo inexplicável e invariavelmente funesto.

A hesitação do leitoré, paraTodorov (1976/ 2007, p. 37), "a primeira condição do fantástico." 0 leitor hesita entre uma explicação racional e uma explicação sobrenatural: ou se trata de uma ilusão dos sentidos, de um produto da imaginação e, nesse 
caso, as leis do mundo continuam a ser o que são (explicação racional); ou, então, o acontecimento realmente ocorreu, é parte integrante da realidade; mas, nesse caso, a realidade é regida por leis desconhecidas para nós (explicação sobrenatural). Se o leitor optar pela explicação racional, a narrativa será tomada na perspectiva do maravilhoso. Se 0 leitoroptarpela explicação sobrenatural, o sentimento de estranheza perpassará a leitura. É por isso que 0 fantástico seria um gênero evanescente.

O conto "O Homem da Areia", publicado em 1817, é uma narrativa a três vozes: Natanael, Clara e o narrador. Inicialmente, o leitor é levado a acreditar nos fatos tais como narrados pelo primeiro narrador, 0 jovem Natanael. No centro da narrativa de Natanael está a figura misteriosa de Coppelius, o advogado e alquimista, que, na infância de Natanael, frequentara a casa da família. Esse visitante é identificado, pelo menino de dez anos, ao personagem de uma história infantil, o Homem daAreia, quearrancava os olhos das crianças que não queriam ir dormir. Uma noite, 0 curioso Natanael esconde-se no gabinete de seu pai paracorajosamentetravarconhecimento com o Homem da Areia e descobrir o que o pai e 0 visitante faziam. Quando 0 pai e 0 visitante iniciam uma experiência alquímica, o menino desmaia. Anos depois, 0 universitário Natanael recebe a visita de Coppola, um vendedor delentes e barômetros. Essa visita tem efeito devastador sobre Natanael, pois ele identifica, em Coppola, a figura de Coppelius, que o remete, novamente, ao Homem da Areia.

Hoffmann escreveu, em 1816, "Nussknacker und Mausekonig" (O Quebra-nozes e O Rei dos Camundongos). Esse conto foi traduzido para a língua portuguesa a partir da adaptação francesa de A. Dumas, com o título, "A história de um quebra-nozes." O conto inicia na noite de Natal, quando Maria, menina de sete anos, é presenteada com um quebra-nozes. Observando o cuidado da menina com o boneco, o pai a encarrega de protegêlo. Mas o que acontece durante a noite? 0 quebranozes ganha vida e luta contra o rei dos camundongos. Esses acontecimentos noturnos são a transposição, para a narrativa presente, de uma história dentro da história contada à Maria pelo padrinho D rosselmayer. Trata-se da "História da noz Krakatuk e da princesa Pirlipata", que narra os acontecimentos que se sucederam ao nascimento de uma princesinha: ela sofre um feitiço lançado pela rainha dos camundongos em vingança contra 0 rei e a rainha; para que o feitiço seja desfeito, entra em cena o jovem sobrinho do habilíssimo inventor D rosselmayer.

No conto "A históriadeum quebra-nozes" destaca-se 0 artifício da história dentro da história. Assim, aquilo que na história dentro da história não encontrou uma solução, isto é, a repetição de um feitiço, é transposto para outro plano, o plano da narrativa presente. Esses acontecimentos, transpostos para a narrativa presente, são vividos, por Maria, como sonho e como brincar.

No conto "O Homem da Areia", o leitor é tomado pelo sentimento de inquietante estranheza por se identificar às vivências do personagem Natanael. No conto "A história de um quebranozes", no trânsito do familiar ao sobrenatural e do sobrenatural ao familiar, ambos se interpenetram, produzindo dúvida quanto à natureza dos acontecimentos narrados. A escolha pela explicação racional é oferecida na narrativa pela personagem da mãedeMaria, que explica o relato dosacontecimentos testemunhados pela filha como efeito de sonho ou delírio febril. A escolha pela narrativa maravilhosa é oferecida pela personagem Maria, que vive com naturalidade esse trânsito de um mundo ao outro, assim como se passa do sonho à vigília.

Por suavez, o conto "O Homem daAreia" caracteriza-sepelairrupção do medo no maisíntimo, no próprio eu. Pois, nesse conto, a irrupção do inexplicável não acontece pela aparição de um fenômeno sobrenatural, porum ser deoutro mundo, mas é o próprio personagem que se transforma ao longo do conto.

\section{A história de Natanael}

A pesquisa freudiana sobre o estranho (a inquietante estranheza) toma o conto " $\mathrm{O}$ Homem da Areia" como uma figuração. Freud (1919a) detém-se na ambiguidade da palavra 'heimlich' que, por um lado, significa o que é familiar e agradável e, por outro, o que está oculto e se mantém fora da vista. 'D a ideia de 'familiar', pertencente à casa', desenvolveu-se a ideia de algo afastado dos olhos de estranhos, algo escondido, secreto; $\mathrm{H}$ eimlich aparece em um sentido diferente, como afastado do conhecimento, inconsciente. Dessa forma, heimlich é uma palavra cujo significado se desenvolve na direção da ambivalência, até que finalmente coincide com o seu oposto, unheimlich. Unheimlich é uma subespécie de heimlich. 
Para Freud (1919a), o que desperta no leitor um sentimento de estranheza é o personagem que dá nome ao conto, e que é sempre reintroduzido nos momentos críticos, o "O Homem daAreia", que, segundo uma lenda, arrancava os olhos das crianças que não queriam dormir. 0 temor em relação a ter os olhos extraídos por um monstro equivale ao temor da castração. Freud (1919a) conclui que o sentimento de estranho, relacionado ao personagem que dá título ao conto, se refere à ansiedade (Angst) pertencente ao complexo de castração da infância.

O ra, uma criança que não quer dormir não seria aquela tomada pela curiosidade sobre o que fazem os pais a sós? A sexualidade dos pais, por sua vez, está relacionada a um ciclo vital: nascimento, casamento, reprodução e morte. E esse ciclo vital remete à pergunta sobre a origem do homem. A pergunta "de onde vim?" pode ser respondida, do ponto de vista desse ciclo vital, pela procriação. D o ponto de vista simbólico, essa pergunta será respondidapelafunção paterna, "à qual corresponde o N ome-do-pai na cadeia significante” (Lacan, 19571958/ 1999, p. 187). A palavra da mãe exerce a função de reconhecimento desse significante que representa o enigma do desejo.

D estacaremos a seguir três cenas:

Cena 1: Ele nos davalivros ilustrados, sentava-se mudo einerte em sua poltrona e expelia espessas nuvens de fumaça, de forma que todos nós ficávamos como que envoltos na névoa. Em noites como essamamãeficavamuito triste[...]e, mal soavam as nove horas, falava--nos: "E agora, crianças, para a cama, paraa cama! O Homem da Areia está chegando, já posso ouvir seus passos." [...] Perguntei à mamãe, enquanto ela nos levava: Mamãe! Quem é mesmo o malvado Homem da Areia que sempre nos separa de papai? Como é ele? "Não existenenhum Homem daAreia, meu filho", respondeuminhamãe. (Hoffmann, 1815/ 2006, p. 76).

Cena 2: [...] A figura aterrorizante do Homem da Areianão saíadaminhacabeça. Suasrelaçõescom meu pai passaram a ocupar cadavez mais a minha imaginação, e um medo insuperável impedia-me de interrogá-lo sobre o assunto, mas, com os anos, sedimentou-se e germi-nou em mim a vontadedeinvestigaro mistério, devero fabuloso Homem daAreia. [...] Nada me agradava mais do queouvirouleraterrorizanteshistóriasdeduendes, bruxas e anões. Mas em primeiro lugar estava sempre o Ho-mem da Areia, que eu desenhava com giz ou carvão, da forma mais estranha e abominável, em mesas, armários e paredes. (Hoffmann, 1815/ 2006, p. 77-78).

Cena 3: "Meu pai abriu as portas de um armário, e então constatei que aquilo que eu sempre pensara ser um armário era na verdade um nicho profundo, onde estava um pequeno fogão. [...] Ah, D eus! Ao inclinar-se em direção ao fogão, meupaipareciaoutro. Umadorcruel econvulsiva parecia metamorfosear seus traços na mais horrenda e repugnante imagem diabólica. Ele se assemelhava a Coppelius! [...] Agora temos olhos - olhos -, um lindo par de olhos infantis." Foi o que murmurou Coppelius, pegando com as mãosum punhado debrasas incandescentes para atirarem meusolhos, enquanto meupaiimplorava, erguendo as mãos e gritan-do: "Mestre! Mestre! Deixe os olhos de meu Natanael - deixe-0s com ele!." (Hoffmann, 1815/ 2006, p. 80).

Se compararmos a primeira e à terceira cena, é possível observar que, se na primeira, o pai não fala, na terceira, sua fala vem interceder pelo filho junto ao Homem da Areia. Isso se relaciona ao que aparece na cena 2, o enigma da relação do Homem da Areia com o pai. Na cena 3, o enigma é revelado e a fala do pai é manifesta.

A cena 1 permite analisar a questão de uma irrupção de algo sem face e para o qual não há senão um nome "O Homem da Areia". Do aterrorizante, do que não consegue falar, 0 personagem consegue apenas fazer desenhos compulsivamente. Na ausência de palavras, há, pelo menos, produção imaginária. Esses desenhos remetem à imagem que o menino faz de um pai castrador, o pai imaginário. Conclui-se que a figura do Homem da Areia representa, para Natanael, 0 pai imaginário e não o pai simbólico.

$\mathrm{Na}$ cena 1, aparece uma ambiguidade no discurso materno. A mãe que anunciara, inicialmente, o Homem da Areia, desmentirá, em seguida, a existência deste. Dessa forma, não ocorre substituição de um significante (o que quer o Outro?) por outro (o Homem da Areia). 0 significante "Homem da Areia", que poderia ter representado uma função de mediação (o Nomedo-Pai), permanecerá identificado ao desejo da mãe, ao Outro imaginário. Como efeito desse processo, o significante "Homem da Areia" não tem a eficácia simbólica de endereçar o sujeito para um outro significante, isto é, para além do desejo da mãe. Esse processo corresponde à foraclusão do Nome-do-Pai. 
A foraclusão do Nome-do-Pai impede 0 reconhecimento simbólico do lugar de sujeito de desejo de saber, assim resta a Natanael desenhar compulsivamente o ogro, assim como ficarà espreita no encontro de seu pai com Coppelius. É nesse encontro que se revelará ao sujeito um saber, pai, Coppelius e Homem da Areia encarnam essa figura de um Outro imaginário, agente de uma castração vivida como real. Essa hipótese explica a sequência da narrativa como delírio e alucinação enquanto derradeiras defesas em relação ao O utro imaginário. D efesa paradoxal através da qual o sujeito se oferece como objeto. "Roda de fogo, gire" alucina Natanael, oferecendo-se, enfim, como objeto para apaziguar esse Outro imaginário que tem o poder de criação ou despedaçamento do autômato.

\section{A história de Maria}

Neste conto, o elemento sobrenatural aparece na transformação operada em um quebranozes, instrumento para quebrar nozes que tem a forma de um soldadinho de madeira. É enquanto boneco que ele vai ganharum lugarjunto às bonecas da menina Maria, de sete anos de idade. Mas o que acontece durante a noite? 0 boneco ganha vida. Esses acontecimentos noturnos ocorrem no contexto de uma história dentro da história, a saber, a "História da noz K rakatuk e da princesa Pirlipata". Essa história será narrada à Maria pelo padrinho D rosselmayer depois de ela lhe ter contado o que vira acontecer à noite. Seria como se fosse uma explicação para os fatos ocorridos à noite?

E não seria essa a função da narrativa, como tentativa de explicação para fatos não compreendidos? Por exemplo, como um boneco pode ganhar vida? Mas, se para o leitor isso merece ser explicado, para Maria, não é o caso de uma explicação, pois, para ela, o mundo da fantasia e 0 mundo da realidade não estão dissociados. Assim, podemos considerar quea história dentro da história pertence ao gênero maravilhoso, que inicia pelo "era uma vez" e narra os acontecimentos que se sucederam ao nascimento de uma princesinhamuito bonita e do feitiço que a rainha dos camundongos teria produzido, transformando-a em uma menina feia, por vingança contra o rei e a rainha, que expulsaram os camundongos do reino.

$\mathrm{Na}$ história da princesa Pirlipata, um habilíssimo mecânico, chamado Christian-Elias Drosselmayer fora chamado pelo rei para fazer as armadilhas contra os camundongos e, mais tarde, para descobrir como desfazer o feitiço. 0 mestre D rosselmayer e 0 astrônomo da corte descobrem que só haviauma solução para tornar Pirlipata novamente bela: a amêndoa da Noz K rakatuk, uma noz de casca tão dura que nem a roda de um caminhão de artilharia pesada podia quebrá-la. E ainda mais: a noz deveria ser partida na presença da princesa e pelos dentes de um jovem que jamais tivesse se barbeado e sempre conservasse as botas nos pés; esse jovem teria de apresentar a amêndoa à princesa, com os olhos fechados, e, sempre com os olhos fechados, deveria recuar sete passos sem tropeçar.

Depois de muitos anos de viagem, D rosselmayer e o astrônomo conseguem localizar a noz Krakatuk e o jovem que preenche as condições e que, coincidentemente, era um sobrinho de D rosselmayer. Realizam-se, então, os procedimentos tal como anteriormente descritos. Entretanto, antes que o jovem realizasse os sete passos para trás, a rainha do s camundongos aparece e vinga-se do jovem que quebrara a noz com os próprios dentes. Este é transformado em um quebra-nozes de madeira. E agora, qual será a solução para quebrar mais um feitiço?

É aqui que a história dentro da história penetra na narrativa no presente. A menina Maria é presenteada, na noite de Natal, com um quebranozes. Ela cuida do quebra-nozes com todo 0 carinho. Ao observar que o quebra-nozes agradara Maria, o pai lhe confere o lugar de protetora deste boneco de madeira.

Podemos, então, iniciar uma análise do brincar na história de Maria. $\mathrm{O}$ brincar é uma forma de realização simbólica do desejo inconsciente. No caso de Maria, esse desejo é reconhecido pelo pai, na medida em que as palavras do pai autentificam, simbolicamente, o desejo de Maria. 0 efeito do reconhecimento do desejo pela via simbólica caracteriza a estrutura psíquica gerada pelo recalque. Pois é na medida em que um significante recalcado encontra uma via de expressão simbólica, isto é, um outro significante que 0 substitui, esse primeiro significante permanecerá recalcado.

E quem é o objeto dos cuidados de Maria? O quebra-nozes ou o jovem sobrinho de Drosselmayer. É então que a história dentro da história vem participar da narrativa presente. 0 jovem sobrinho do personagem Drosselmayer, quebrando a noz Krakatuk com os próprios dentes, desfizera um feitiço. Eis aqui os elementos 
característicos do conto de fadas: uma princesa, um feitiço, um herói destinado a romper um feitiço. Mas, ao realizar o destino de desfazer o feitiço, 0 herói sofrera um outro feitiço, ao ser transformado em um quebra-nozes de madeira. A rainha dos camundongos agora está morta, mas seu herdeiro, 0 rei dos camundongos ainda pretende executar a vingança, agora contra o quebra-nozes. Mudam os personagens, mas o feitiço se repete. Eis que a história dentro da história entra na própria história narrada presentemente.

O conto de Hoffmann "A história de um quebra-nozes" rompe, então, com a estrutura do conto de fadas ao transportar um personagem de conto de fadas para a cena atual. Há dois personagens que transitam pelas duas histórias, 0 padrinho D rosselmayer e seu sobrinho (aquele que fora transformado em um quebra-nozes). D rosselmayer é a figura misteriosa que pertence aos dois mundos, como o inventor que assessorava o rei em um conto de fadas; e, na narrativa presente, é o padrinho dotado da habilidade de inventar e consertar mecanismos da narrativa presente.

O conto, "A história deum quebra-nozes", devido à transição natural entre 0 mundo da imaginação e o mundo cotidiano, tal como é vivida pela personagem Maria, poderia ser classificado no gênero do maravilhoso, como um conto de fadas. Se, para Maria, o trânsito entre o sobrenatural e 0 familiar é natural, para o leitor, é justamente a irrupção do mundo maravilhoso no mundo familiar que produz a pergunta: será que foi sonho da personagem ou realmente os personagens do conto defadas (dahistória dentro dahistória) estão atuando neste mundo real? Pois é a participação de Maria, através do cuidado que ela dedica ao quebra-nozes de madeira, que faz com que se desfaça o feitiço da rainha dos camundongos.

O que importa destacar é o artifício narrativo da história dentro da história utilizado pelo autor E. T. A. Hoffmann. Ora, uma história dentro da história não equivaleria ao sonho dentro do sonho? Segundo Freud (1900), no sonho dentro do sonho, não há algo a ser interpretado, pois 0 sonho dentro do sonho éa própria coisa, éo próprio pensamento onírico coberto por um disfarce.

O que é sonhado num sonho, depois que se acorda do sonho dentro do sonho, é o que 0 desejo procura colocar no lugar de uma realidade obliterada. É seguro supor, então, que o que foi sonhado no sonho é uma representação da realidade, a verdadeira lembrança, ao passo que a continuação do sonho, pelo contrário, meramente representa o que o sonhador deseja. (Freud 1900/ 1987, ESB, IV, p. 321).

Assim, também, do sonho de Maria nada há a interpretar. Seu sonho é o próprio maravilhoso. Mas o que é fantástico nessa história é que o sonho dentro do sonho se tornou real, Maria cuida de um quebra-nozes sabendo (inconscientemente) queesse quebra-nozes é, na verdade, um rapaz. Eis aqui 0 desejo inconsciente de Maria enquanto saber inconsciente. Se, quando ela ganha o presente, ela ainda nada sobre a "História da noz Krakatuk e da princesa Pirlipata" , mesmo assim, ela trata o quebranozes como se esse fosse uma pessoa. Esse modo de lidar com os brinquedos faz parte do contexto do brincar. É só depois, quando ela escuta a "História da noz Krakatuk e da princesa Pirlipata”, que poderá imaginar que esse boneco é, na verdade, um rapaz que foi transformado em boneco eisso explica por que ele ganha a vida à noite. Logo, não é no campo do onírico nem do delírio febril que será preciso situar os acontecimentos noturnos da luta de quebra-nozes contra o rei dos camundongos.

Assim, não poderíamos afirmar que ela se enamorou do personagem que saiu do conto de fadas. Mas que é seu amor por esse personagem que quebra o feitiço que o condenaraà forma de quebranozes de madeira. Esse é o fantástico enquanto inefável no conto "A história de um quebra-nozes".

Assim poderíamos considerarque ahistória dentro da história entra na narrativa presente como uma repetição, ou seja, o que se repete, se repete para encontrar uma solução. Essa solução será a transposição paraoutro registro, o registro danarrativa presente. E como a repetição encontrará fim?A través dos cuidados de Maria, dissolve-se o feitiço, isto é, a repetição. Ambas as histórias terminam. Nesse conto, estranho e maravilhoso se conjugam.

\section{Maria brinca, $\mathbf{N}$ atanael alucina}

Um sintoma, um sonho traumático ou uma alucinação são processos inconscientes. Dizemos, por intermédio de uma metáfora, que "buscam" uma solução. A solução seria o cessar de se repetir. Esse repetir poderia ser tomado ou como próprio de uma iteração ou como sucessão 
ou série. O s números fazem uma série porque vêm um depois do outro, ou seja, se sucedem no tempo. Já em uma iteração, o tempo é sempre o tempo presente, não há passado. O u melhor, o passado é 0 eternamente presentificado. Para desenvolver essa ideia pode-se utilizar a distinção entre "simbolicamente real" e "realmente simbólico".

Trabalhamos essa oposição a partir da contribuição de Didier-Weill (2007) ao estudo do Seminário, livro 24 de Lacan (1976-1977/ 1998):

Por realmente simbólico, Lacan evoca 0 simbólico, ou seja, o inconsciente enquanto simbolicamente incluído no real, enquanto que por simbolicamente real, ele evoca o que do real se conota no interior do simbólico. Tratase aqui da diferenciação entre dois estados do significante. $\mathrm{O}$ significante tal como ele é articulado no inconsciente é este pelo qual o sujeito é levado a falar como falasser (parlêtre) enquanto que o significante queé articulado no simbolicamente real é um significante que não se presta ainda para a fala: ele encarna isso pelo qual a fala virá a ser, em um futuro onde 0 inconsciente será articulado. (Didier-Weill, 2007, p. 3). [Tradução nossa].

No caso do conto "A história de um quebra-nozes", se, antes, era Pirlipata, agora, é o quebra-nozes que sofre o feitiço. Mas o real, ou seja, o sintoma, aqui comparado ao feitiço, continua, itera. Em "O Homem da Areia", também encontramos uma iteração em Coppelius que toma a forma de Coppola.

Por outro lado, é preciso considerar 0 realmente simbólico. É aqui que entra o brincar. No brincar háumatransposição paraoutro registro. Brincase, quando se coloca um significante no lugar do real. 0 real estará presente, mas através da mediação do significante. Essa mediação pode ser encontrada na brincadeira de "fort-da" do neto de Freud. Sobre esse famoso jogo de carretel, Lacan (1964/ 1985, p. 63) afirmou: "O carretel não éa mãe, mas é algo do sujeito quesedestaca, ou seja, o significanteenquanto primeira marcado sujeito." E justamente porque aquele carretel não era mãe nem o menino que ele era um significante. Assim, aquele carretel, enquanto suporte para receber uma marca do significante, constitui uma exemplificação do "realmente simbólico".

Há algo que não nos é dado a ver, há algo que não podemos saber. No entanto, é possível representar essa separação ou perda, brincando com o que não podemos saber. Colocando significantes no lugar do que não nos é dado ver. A castração representa o corte, ou seja, o não-saber como separação entre o sujeito e algo que a ele é vedado. A partir dessa instauração de um nãosabido, institui-se uma falta enquanto busca de saber. Esse saber passa a ser suposto em um O utro, o qual, enquanto lugar dos significantes, instaura e permite a substituição de um significante por outro.

Ao invés de brincar, de fazer metáfora com o quenão lheédado saber, Natanael testemunha o desejo do Outro. A história do Homem da Areia como figura ameaçadora para as crianças não 0 convence de que há algo que não nos é dado a ver nem a saber, pois que não se pode retornar à cena originária, à cena da concepção da qual estamos para sempre perdidos.

Ao espiar o que não lhe é dado a ver, Natanael desmaia, ou seja, desaparece como sujeito perante a cena de criação de autômatos. Essa cena pode ser interpretada como uma transposição hoffmanniana do "fazer bebês". Freud se referia à cena primária como a fantasia referente ao coito dos pais, fantasia relacionada às teorias sexuais infantis. Em Hoffmann, encontramos uma cena equivalente encenada pela dupla Homem da Areia e pai de Natanael. E, assim como Freud descobrira que não se trata de precisar se a criança observou ou não a cena primária, mas sim de escutar a teoria que se origina de uma fantasia, aqui também, se trata de examinar a cena alquímica e o desmaio de Natanael como fazendo parte de uma teoria sexual infantil. Mas em que se diferencia essa cena das teorias sexuais infantis? Natanael constrói uma cena na qual ele próprio é 0 objeto de despedaçamento. 0 que poderia ficar no campo da fantasia se torna real. O sujeito sai de cena e passa a ser o próprio objeto.

E aqui podemos confrontar essa vivência de Natanael com a gramática que Freud (1919b) analisa em "Umacriançaé espancada". Nasfantasias recolhidas por Freud, o sujeito era representado por uma outra criança como uma forma de mediação simbólica entre 0 sujeito e o Outro. No caso de Natanael, a ausência de uma mediação simbólica faz com que ele próprio se torne o objeto do experimento alquímico.

Essa cena representa 0 encontro com 0 desejo do O utro. Na narrativa, esse desejo aparece figurado namanipulação alquímicaenquanto criação de seres. Sem a mediação simbólica, esse desejo se torna tão aterrorizante que Natanael desmaia. Ao 
desmaiar, ele se torna objeto manipulado no experimento alquímico, pois vive a experiência alquímica como fragmentação do próprio eu. Essa vivência alucinatória de Natanael remete ao simbolicamente real, isto é, àquilo para 0 qual 0 sujeito não encontra palavras.

Uma complementação da análise dessa cena pode ser realizada à luz da concepção do objeto a. $\mathrm{O}$ objeto a, enquanto objeto perdido, representa a divisão do sujeito, a castração, a perda e também a falta no O utro. Lacan (1964/ 1985) vai denominá-lo objeto causa do desejo. Este objeto caído, perdido, separado do sujeito, éo queNatanael reencontra. Mas é por que o objeto está perdido que não pode mais ser reencontrado, a não ser como fantasia ou alucinação. Como vimos, sem uma mediação simbólica não é possível fantasiar esse reencontro. A Natanael resta uma vivência alucinatória desde o lugar de objeto para um O utro.

Em contraste, Maria questiona o adulto sobre o queconsideraestranho, por exemplo, pergunta ao padrinho D rosselmayer o que ele estava fazendo sentado sobre um relógio durante a noite. Essa cena da história de Maria poderia se assemelhar a uma alucinação, não fosse 0 fato de a menina acordar e questionar o adulto ao falar sobre seu sonho. 0 uso da fala enquanto expressão de desejo ou temor mostra que as relações entre os significantes são operantes. E nesse aspecto que Maria representa a estrutura de sujeito psíquico constituída pela eficácia simbólica, pois a fala do pai reconhece o desejo em Maria. Nesse reconhecimento, o significante primordial relacionado ao desejo do Outro (no caso, o pai), fica recalcado (inconscientizado) sob o significante do cuidado. Está dado, portanto, o encadeamento significante a partir do recalque de um significante primordial relacionado ao desejo do Outro.

\section{CONSIDERAÇÕES FINAIS}

O estudo de traços de dois personagens da literatura, à luz da teoria psicanalítica do psicopatológico, revelou queafunção do significante na estrutura do sujeito psíquico é condição fundamental para se analisar a diferença entre as formas de estruturação neurótica e psicótica. Estabelece-se, ainda, uma relação com a clínica, na medida em que os elementos das estruturas que correspondem ao recalque e à foraclusão são analisados a partir de dois casos exemplares.
Um outro resultado deste estudo envolve o próprio processo de pesquisa. O u seja, a busca de termos de comparação entre a teoria psicanalítica do sujeito psíquico e traços dos personagens literários exige a realização de uma abstração dos elementos da estrutura chamada sujeito psíquico.É nesse sentido que vislumbramos que a aplicação do método comparativo da forma como foi realizado neste estudo, isto é, a comparação entre conceitos psicanalíticos e traços de personagens da literatura, tem vocação de transposição com finalidade didática. Neste trabalho, a transposição tomou a forma da construção de caso na medida em que os personagensforam analisados como sefossem casos clínicos E nesse sentido que este estudo contribui para 0 enriquecimento dos métodos de ensino e aprendizagem na área de psicologia com enfoque em psicologia do desenvolvimento e psicopatologia.

\section{REFERÊNCIAS}

Caillois, R. (1997). Dictionnaire des genres et notions littéraires. Paris: Encyclopedia Universalis \& Albin Michel.

Calvino, I. (1983/ 2004). Contos fantásticos do século XIX escolhidos por Italo Calvino. São Paulo: Companhia das Letras.

Carvalhal, T. (O rg.). (1994). Literatura comparada: Textos fundadores. Rio de Janeiro: Rocco.

Didier-Weill, A. (2007). Le symboliquement reel n'est pas le reelement symbolique. Recuperado em 22 jun. 2008: http:/ / w w w. in sistance.as so.f r/ P D F/ Symboliquiement-reel_Didier-Weill.pdf

Freud, S. (1950/ 1987). Obras psicológicas completas de Sigmund Freud (2a ed). Tradução e revisão de por Jayme Salomão. Rio de Janeiro: Imago.

Freud, S. (1900). A interpretação dos sonhos. (vols. 4-5) Rio de Janeiro: Imago.

Freud, S. (1919a). 'Uma criança é espancada' (vol 17): Uma contribuição ao estudo da origem das perversões sexuais. Rio de Janeiro: Imago.

Freud, S. (1919b). O 'estranho'. (vol. 18) Rio de Janeiro: Imago. 
Hoffmann, E. T. A (1815/2006). O homem da areia. In F. M. Costa, da. (O rg.). (2006). Os melhores contos fantásticos. (pp. 73-106). Rio de Janeiro: Nova Fronteira.

Hoffmann, E. T. A. (1816/ 1971). História de um quebra-nozes. Adaptação de A. D umas. Tradução de Guilherme de Figueiredo. Rio de Janeiro: Edições $\mathrm{O}$ uro.

Lacan, J. (1957-1958/ 1999). O seminário livro 5: As formações do inconsciente. Rio de Janeiro: Jorge Zahar.

Lacan, J. (1964/ 1985). 0 seminário livro 11: 0 s quatro conceitos fundamentais da psicanálise. Rio de Janeiro: Jorge Z ahar.

Lacan, J. (1976-1977/ 1998). O seminário Livro 24: L'insu que sait de l'une-bévue s'aile à mourre. Publicação não comercial da Association Freudienne Internationale: Paris.

Todorov, T. (1976/ 2007). Introdução à literatura fantástica. São Paulo: Perspectiva.

Recebido: 24/ 09/2008

Received: 09/24/ 2008

Aprovado: 06/ 12/ 2008

A pproved: 12/ 06/ 2008 